\title{
Community-Based Disability Prevention Programs for Elders: Predictors of Progam Completion
}

\author{
ALMAS DOSSA \\ Center for Health Quality, Outcomes, and Economic Research, \\ ENRM Veterans Hospital, Bedford, Massachusetts, USA \\ JOHN A. CAPITMAN \\ Central Valley Health Policy Institute; and College of Health and Human Services, \\ California State University, Fresno, Fresno, California, USA
}

\begin{abstract}
Strategies to foster elder well-being and reduce long-term care costs include efficacious community disability prevention programs. Program completion remains an important barrier to their effectiveness. We examined the association between provider relationships and client variables, and program completion in senior centers. Our mixed methods design used secondary data for 719 clients and primary data through telephone interviews with 20 nurses, 23 social workers, and 18 site managers. Quantitative data showed that bigher client baseline self-efficacy positively influenced completion and minority status negatively influenced completion. Qualitative data showed that bigher focus on provider-client relationships was associated with bigh completion.
\end{abstract}

Received 25 March 2009; accepted 3 December 2009.

The research was conducted in partial fulfillment of the doctor of philosophy degree requirements for Almas Dossa, Heller School for Social Policy and Management, Brandeis University. We thank the other dissertation committee members, Suzanne Leveille, PhD, Walter Leutz, PhD, and Sarita Bhalotra, PhD, for their participation. This research was supported in part by a grant from the Foundation for Physical Therapy.

We are grateful to Susan Snyder, Vice President, Senior Services, Seattle, WA; Elizabeth Phelan, MD, and Barbara Williams, PhD, University of Washington; Jody Gittell, PhD, Brandeis University; Terence Tivnan, PhD, Harvard University; Silvana di Gregorio, PhD, SdG Associates; and to the nurses, social workers, and site managers who participated in the study.

Address correspondence to Almas Dossa, PhD, MPH, Center for Health Quality, Outcomes, and Economic Research, ENRM Veterans Hospital, 200 Springs Road (152), Bedford, MA 01730, USA. E-mail: adossa@bu.edu 
KEYWORDS Communityprograms, program participation, provider relationships, self-efficacy, minorities

\section{INTRODUCTION}

Although recent studies indicate declining disability rates among elders in the United States, health and social service requirements of disabled elders represent an increasing challenge due to expected growth in the population of elders (Manton, XiLiang, \& Lamb, 2006; Stuck, Walthert, \& Nikolaus, 1999). Several randomized controlled trials using disability prevention models such as the Chronic Disease Self-Management Programs (CDSMPs) and the Health Enhancement Program (HEP) now known as Enhance Wellness for elders with chronic disease are reported to improve functional outcomes, improve exercise tolerance, decrease hospitalization, and improve quality of life (Leveille et al., 1998; Lorig, Ritter, 2001; Phelan et al., 2002; Phelan, Williams, Pennix, LoGerfo, \& Leveille, 2004; Phelan, Williams, Snyder, Fitts, \& LoGerfo, 2006). Recruiting and engaging elders to participate in any type of health program and to complete such programs, however, is challenging (Eakin \& Russel, 1997; Ory et al., 2002; Prohaska, Peters, \& Warren, 2000; Wagner, Grothaus, Hecht, \& LaCroix, 1991). Program noncompletion or refusals impair health outcomes (Clark, Stump, \& Damush, 2003; Minder, Muller, Gillmann, Beck, \& Stuck, 2002).

A range of factors may influence program completion, among them client factors such as socio-demographic factors and health related factors, and provider factors including relationships between providers and relationships between providers and clients. Self-efficacy, a key construct in social cognitive theory, is defined as belief in one self to perform a certain activity or behavior (Bandura, 1977). Higher baseline self-efficacy may enhance program adherence and health outcomes, but studies in this area have focused on exercise adherence and not on self-management programs such as the HEP (King, 2001). Other studies on CDSMPs reported significant associations between lower baseline self-efficacy and lower program completion, but used weaker bivariate models rather than stronger multivariate models to test for differences between completers and noncompleters (Lorig, Gonzalez, Laurent, Morgan, \& Laris, 1998; Lorig, Ritter, et al., 2001). Another study found insignificant associations between baseline self-efficacy and exercise adherence for older adults, but used correlation coefficients to test this association (Brassington, Atienza, Perczek, Lorenzo, \& King, 2002).

Additionally, the research on the association between minority status and program completion has produced mixed results. In some studies, client drop-outs were more likely to be non-White (Leutz et al., 2002; Lorig, Sobel, Ritter, Laurent, \& Hobbs, 2001). However, in Phelan's HEP study where 
strong recruitment efforts were used, significant race differences in drop-outs were not observed (Phelan et al., 2002). Other client factors associated with low program completion include depression (Castro, Wilcox, O'Sullivan, Baumann, \& King, 2002), lower self-perceived health (Clark et al., 2003), higher age, lower activity level, female status, high body mass index (BMI), being unmarried, and chronic disease (Carter, Elward, Malmgren, Martin, \& Larson, 1991; Grace, Abbey, Shnek, \& Irvine, 2002; Leutz et al., 2002; Lorig, Ritter, et al., 2001; Lorig, Sobel, et al., 2001; Lorig et al., 1999; Mills et al., 1996; Phelan et al., 2002).

The importance of provider-client relationships in program adherence across a range of settings has been well established where positive perceptions of the patient-provider relationship directly impacted adherence to diet, exercise, and diabetes management attitudes (Maddigan, Majumdar, \& Johnson, 2005). Strong provider-client relationships can improve outcomes, but most research in this area has focused on patient adherence to medications, outcomes in chronic illnesses, or research study retention, rather than program completion (Leonard et al., 2003; Stewart, Brown, \& Donner, 2000; Von Korff, Gruman, Schaefer, Curry, \& Wagner, 1997). Other provider and provider-client/family relationship models focus on relationship-centered care, where individuals are seen as belonging to a network of social relationships; relationships are mutually empowering; and trust, empathy, and respect exists between participants, thus leading to improved patient self-management and patient adherence to treatment (Beach \& Inui, 2006; Duggan, 2006; Nolan, Davies, Brown, Keady, \& Nolan, 2004).

Provider relationships and provider-client relationships can be measured by relational coordination, which is one type of communication and relationship-intensive form of coordination between providers and between providers and clients (Gittell, Fairfield, Bierbaum, Head, \& Jackson, 2000). Communication (frequency, timeliness, and problem-solving dimensions) and relationships (shared goals, shared knowledge, and mutual respect) are important elements of the coordination process, and are mutually reinforcing (Gittell, 2006). Communication is influenced by relationships between workers, and these relationships are influenced by the nature of their communication. This enables participants to effectively coordinate work processes. For instance, high relational coordination between providers and also between providers and caregivers for patients following total knee replacement surgery has significant effects on the quality and efficiency of patient care (Gittell et al., 2000; Weinberg, Lusenhop, Gittell, \& Kautz, 2007)

Program completion research on elder health programs primarily focuses on exercise adherence, rather than on broader wellness programs such as the HEP (Brassington et al., 2002; King, 2001; Prohaska et al., 2000). Although both client factors and provider relationship factors may affect program completion, there has been little research on these factors for the HEP. The HEP randomized trial (Leveille et al., 1998) and dissemination 
study (Phelan et al., 2002) demonstrated both the efficacy of the intervention and the difficulty of enrolling elders and getting them to complete programs. As yet, we have no studies on client self-efficacy or provider influences on adherence for the HEP, and the effects of minority status varies in different studies. In this study, we aimed to (a) examine the association between client characteristics (self-efficacy and minority status) and program completion, (b) examine the association between provider relationships and program completion, (c) examine the association between provider-client relationships and program completion, and (d) obtain provider perspectives on program completion. We expected higher client baseline self-efficacy, nonminority status, high relational coordination, and high provider focus on client relationships to lead to higher rates of program completion.

\section{PROGRAM BACKGROUND}

The HEP is a component of the Senior Wellness Project and was developed by the Northshore Senior Center and the University of Washington, Seattle. Conducted by nurses and social workers in senior centers, HEP was designed to promote health and functioning of community elders with chronic disease at risk for functional decline, and consists of comprehensive health reviews, functional assessments, action plans, and support groups (Leveille et al., 1998). Following the assessment, clients return within 2 weeks to review plans, then 6 and 12 months later for assessments. The Health Mentor program, another component, matches HEP clients to trained elder peer mentors who provide follow-up calls and support for the health action plan (Davis, Leveille, \& Favaro, 1998). Additionally, the client is encouraged to enroll in other evidence-based program components: an exercise class and the CDSMP, a 6-week program including guidelines on goal setting, exercise, medications, coping, symptom management, and communication with health professionals (Lorig, Sobel, et al., 2001).

\section{METHODS}

Our mixed methods design used secondary longitudinal data from 2002-2004 for 719 clients (owned by the University of Washington), primary relational coordination data on provider relationships and provider-client relationships, and primary qualitative data on provider perspectives on elder participation. The design was primarily quantitative, with a concurrent supplementary qualitative component (Curry, Shield, \& Wetle, 2006). To enhance our quantitative data on provider-client relational coordination and client self-efficacy, we also asked our providers (nurses and social workers) open-ended questions 
on how and why clients engage in and complete programs focusing on client self-efficacy and provider-client relationships. We conducted this study with all 22 HEP sites located in the United States (14 sites in Washington State, five sites in Michigan, one site in Maine, and two sites in New York). We collected primary data through provider and site manager telephone interviews (20 nurses, 23 social workers, 18 site managers) from February 2004 to June 2004. The audio-taped interviews varied from 20 to $90 \mathrm{~min}$.

\section{Independent Measures}

Main independent client variables included exercise and physician relationship self-efficacy and minority status. Self-efficacy was a continuous variable and minority status was a categorical (Yes/No) variable because the data set did not contain information on specific minority categories. Control client variables (see Table 1 for detail) included demographics; validated measures of health status variables (Ware \& Sherbourne, 1992); depression (Yesavage, Brink, \& Rose, 1982); functional status variables such as activities scale, physical activity readiness scale, walk status, and ability to shop/cook

TABLE 1 Client Level Baseline Descriptive Data

\begin{tabular}{|c|c|c|c|c|c|}
\hline Variables & $\mathrm{n}$ & $\mathrm{M}$ & SD & Range & Percentage $(\%)$ \\
\hline \multicolumn{6}{|l|}{ Continuous variables } \\
\hline Age at baseline visit & 657 & 73.73 & 9.45 & $45-97$ & \\
\hline Depression Index & 698 & 3.96 & 3.49 & $0-15$ & \\
\hline $\begin{array}{l}\text { Self efficacy scale ( } 0-10 \text { confidence } \\
\text { scale, } 3 \text { questions on exercise } 3 \\
\text { questions on talking to providers) }\end{array}$ & 624 & 37.82 & 12.98 & $0-54$ & \\
\hline Activities/role limitations scale (SF36) & 634 & 29.36 & 6.22 & $5-36$ & \\
\hline Number of prescription drugs & 632 & 4.96 & 3.31 & $0-18$ & \\
\hline Body mass index (BMI) & 632 & 29.08 & 6.69 & $16-66$ & \\
\hline \multicolumn{6}{|l|}{ Categorical variables $(0,1)$} \\
\hline Gender (= 1 if female $)$ & 710 & & & & 74 \\
\hline Minority (= 1 if minority) & 644 & & & & 9 \\
\hline $\begin{array}{l}\text { Health status ( }=1 \text { if health status } \\
\text { compared to } 12 \text { months ago is better } \\
\text { or same) }\end{array}$ & 708 & & & & 33 \\
\hline $\begin{array}{l}\text { Self-reported health status ( }=1 \text { if good, } \\
\text { very good, excellent) }\end{array}$ & 707 & & & & 71 \\
\hline $\begin{array}{l}\text { Physical activity } 11 \text { measure readiness } \\
\text { scale (converted to } 3 \text { stages and } \\
\text { binary with precontemplation and } \\
\text { contemplation vs. active and above) }\end{array}$ & 711 & & & & \\
\hline Precontemplation stage & & & & & 6 \\
\hline Contemplation stage & & & & & 56 \\
\hline Active stage and above & & & & & 38 \\
\hline $\begin{array}{l}\text { Walk status (self-report, = } 1 \text { if walked } \\
\text { greater than one block) }\end{array}$ & 668 & & & & 68 \\
\hline Inability to shop/cook in last 6 months & 700 & & & & 16 \\
\hline
\end{tabular}


(Ainsworth \& Youmans, 2002; Long, Calfas, \& Wooten, 1996; Ware \& Sherbourne, 1992); number of prescription drugs (used for chronic disease status); marital status; and BMI. Client data were recorded by nurses at baseline level, 6 months, and 12 months. We dropped variables if they had more than 15\% missing data (education, income, English first language).

For the relational coordination constructs we used an instrument (closeended survey and available on request) developed and tested by Gittell et al. (2000), and used similarly in hospital and nursing home settings. We followed standardized guidelines to construct variables. Questions for the nurse and social worker were asked based on five dimensions, which included two communication questions (frequency of communication and problem solving) and three relationship questions (shared goals, shared knowledge, and shared respect). We asked nurses and social workers to respond on their communication and relationships with other providers and clients/family by thinking about typical patterns and current working conditions to avoid response error. For example, one relationship question included "How much do these people respect your contribution to the program?" One communication question included, "When issues arise, do these people work with you to solve the problem?" We measured responses on a 5-point Likert scale ( $1=$ not at all to $5=$ completely) and used provider mean responses at each site. Responses were calculated to form three indexes: Staff relational coordination (relational coordination between site staff, i.e. site manager, fitness leader, CDSMP leader, health mentor, nurse, and social worker $=25$ items, Cronbach's coefficient alpha $=0.85$ ); PCP relational coordination(relational coordination between primary care physician and nurse/ social worker $=5$ items, Cronbach's coefficient alpha $=0.83$ ) and client/family relational coordination (relational coordination between client/family and nurse $/$ social worker $=10$ items, Cronbach's coefficient alpha $=0.80$ ). We also determined an overall relational coordination score from means of Staff, PCP, and Client/family relational coordination.

\section{Dependent Measure}

We defined program completion as a binary variable where $0=$ completion of baseline input session only, and $1=$ completion of at least the baseline and 6-month visit, or baseline, 6-, and 12 month visit, since recent changes in the program (as of 2004) described completion at 6 months instead of 12 months, and we did not have specific details on exact dates for initiation of this change for each site.

\section{Quantitative Analysis}

We computed correlation coefficients between independent variables to test for multicollinearity, conducted descriptive analyses of demographic and 
health status variables, and conducted bivariate analyses using chi-squares or logistic regressions to test independent variable and program completion association. We analyzed program completion client predictors using binary mode generalizing estimating equations (GEE), which were conducted to account for correlated error issues associated with client clustering within sites (Horton \& Lipsitz, 1999). We added the relational coordination constructs one at a time. We used SAS version 9.1.

\section{Qualitative Analysis}

Interviews were transcribed verbatim, reviewed for accuracy, and transcriptions entered into Atlas.ti software. We used a thematic coding technique where we attached labels to specific sections (Coffey \& Atkinson, 1996). We coded transcript segments together to ensure validity, and discussed theme formation. We identified patterns to determine relationships between provider perspectives on participation and program completion. For purposes of this article, we focused on two models based on interviews with the providers: a provider-client relationship model and a client self-efficacy model. We explore their relationship with program completion.

\section{QUANTITATIVE RESULTS: DESCRIPTIVE DATA}

The final data set had 18 sites with 719 clients, because we excluded four sites that had less than 10 clients. Out of the 719 clients who came to the first session, 551 clients came to the 6 or 6- and 12-month sessions, representing a $77 \%$ completion rate. Table 1 shows the client level baseline values. Correlation coefficients between independent variables were all below .5 . Thirty-nine percent of sites had active health mentor programs. All respondents were women except for one nurse and two site managers, with age range from 39-65 years. All were Caucasian, except for one nurse who was Asian.

Bivariate analysis showed significant positive associations between program completion and self-efficacy (Table $2, p<.05$ ); significant negative associations between minority status and program completion (Table 3,

TABLE 2 Bivariate Logistic Regression for Program Completion and Self-Efficacy

\begin{tabular}{lcccc}
\hline Baseline client variable & Coeff & SE & OR & CI \\
\hline Intercept & $0.71^{*}$ & 0.290 & & \\
Self-efficacy & $0.02^{*}$ & 0.007 & 1.02 & $1.004,1.03$ \\
\hline
\end{tabular}

Note. $N=624$, Log Likelihood $=619.47^{*}$.

$* p \leq .05$. 
TABLE 3 Bivariate Chi-Square Test for Program Completion and Minority Status

\begin{tabular}{llc}
\hline & \multicolumn{2}{c}{ Program completion } \\
\cline { 2 - 3 } Baseline client variable & Yes & p Value \\
\hline Minority status & & \\
No & $81 \%$ & .0002 \\
Yes & $60 \%$ & \\
\hline
\end{tabular}

Note. $N=644$.

TABLE 4 Bivariate Logistic Regression for Program Completion and Staff Relational Coordination

\begin{tabular}{lrccc}
\hline Baseline client variables & Coeff & SE & OR & CI \\
\hline Intercept & $4.40^{*}$ & 0.98 & & \\
Staff relational coordination & $-0.05^{*}$ & 0.02 & 0.95 & $0.92,0.98$ \\
\hline
\end{tabular}

Note. $\mathrm{N}=719$ Log Likelihood $=781.78^{* * *}$.

${ }^{*} p \leq .001$.

TABLE 5 Generalizing Estimating Equations Model for Program Completion and Client Variables

\begin{tabular}{lcccc}
\hline Baseline client variables & Coeff & SE & OR & CI \\
\hline Intercept & $0.82^{* *}$ & 0.290 & 2.27 & $1.300,4.01$ \\
Minority status & $-1.14^{* *}$ & 0.430 & 0.32 & $0.140,0.74$ \\
Self-efficacy & $0.02^{*}$ & 0.008 & 1.02 & $1.004,1.04$ \\
\hline
\end{tabular}

Note. Control variables included: age, gender, activities scale (SF 36), depression, number of prescription drugs, BMI, health status, physical activity readiness, marital status, functional status variables. $N=571$, Log Likelihood $=263.92^{* * * *}$.

${ }^{*} p \leq .05 .{ }^{* *} p \leq .01 .{ }^{* * * *} p \leq .001$.

$p=.0002$ ), and significant negative associations between program completion and staff relational coordination (Table $4, p=.0009$ ).

The GEE model (Table 5) showed that controlling for the effects of the other variables, the odds for completion was higher with each one level increase in baseline self-efficacy (OR: 1.02, $p \leq .05$ ), and the odds for completion for minorities was less than that of nonminorities (OR: $0.32, p \leq .01$ ). Health status variables, age, gender, marital status, functional status variables, depression, body mass index, and prescription drugs were insignificant. Relational coordination variables when added to the model were insignificant.

Because the full sample of 719 was reduced to 571 in the completion model, we further evaluated the full sample for missing baseline variables. 
Thirteen percent of clients had missing data on the self-efficacy variable and $10 \%$ of clients had missing data on the minority variable. Imputation for self-efficacy was significant for depression and self-rated health, which gave us a sample of 701 with an adjusted $R$-square of only $11 \%$. Because imputation did not prove helpful, we decided to accept the original model. We further evaluated the data using chi-squares to test program completer and noncompleter association with missing baseline variables. Program completers were significantly less likely to have missing baseline values for all variables $(p<.0001)$. Additionally, we examined client-level differences between clients with and without any missing baseline data. We found that missing data were significantly higher for younger clients compared to older clients $(p=.002)$ and that minorities, unmarried clients, and clients with poor/fair health were significantly more likely to have missing baseline data, compared to nonminorities, married clients, and those with good/very good/ excellent health status respectively $(p=.005 ; p=.02 ; p=.008)$.

\section{QUALITATIVE RESULTS}

The qualitative interviews supplemented the quantitative results by exploring perspectives on participation for 20 nurses, 23 social workers, and 18 site managers from the full sample of 22 senior center sites. We discuss one specific theme in this article, that is, the provider-client relationship model versus the self-efficacy model, and site patterns noted. When providers were asked "What do you believe makes the difference to get HEP clients to engage in and complete programs?" they varied in their responses. Some providers perceived that it was their connection and rapport with elder clients that made the difference in program completion and engagement, i.e., provider-client relationship model providers. These providers used words such as caring, support, connection, listening, respect, and trust.

I would like to improve retention of clients and I think feeling a personal connection with the HEP staff or the senior center community helps a great deal. If they feel connected and cared about, that is important. (Social Worker)

I think it is around the personal relationships that are established with people that really encourages people and makes them feel more comfortable and to want to adjust behavior change. (Nurse)

Other providers felt it was the client's self-motivation and self-efficacy that made a difference to why they participated. These providers were designated self-efficacy model providers. 
They also have to have that motivation to want to make the change. (Nurse)

They have to believe they can make a change that will do them some good. (Nurse)

Some providers believed in a combination of the client's self-efficacy as well as the provider relationship.

I think what makes the difference is that they believe that a difference can be made and that they have people to support them in that endeavor not do it for them but to encourage them. You gave me hope and I felt that you really cared that I made a difference. (Nurse)

To determine patterns between program completion and the two models, we established high and low completion rates for sites. Out of the 22 sites, 13 sites had high completion rates (80\% or greater) and 9 sites had low completion rates ( $<80 \%$ completion). Patterns between site completion and models showed that high completion sites had a higher percentage of relationship model providers or combined models (78\%) compared to low completion sites (38\%). Additionally, high completion sites had a higher percentage of health mentor programs (44\%) compared to low completion sites (31\%).

\section{DISCUSSION}

Both client and provider characteristics influenced program completion in this study. Baseline client self-efficacy was significantly associated with program completion. This work is consistent with other studies that show self-efficacy to be a particularly powerful predictor of many health outcomes, including smoking cessation, diet guideline adherence, and exercise adherence (Marks, Allegrante, \& Lorig, 2005). Additionally, minority status was significantly associated with program completion. We also found significant bivariate negative associations between program completion and staff relational coordination (provider relationships). Further, high completion site providers were distinguished from providers in low completion sites by their recognition of the importance of client relational building. Sites with health mentor programs (another type of relationship model) had higher completion rates.

The finding that minority status was associated with lower rates of program completion is consistent with other studies (Leutz et al., 2002; Lorig, Soble, et al., 2001), but it differs from a previous HEP study that showed no association between minority status and program completion (Phelan et al., 2002). We attribute this finding to stronger recruitment efforts 
and involvement of primary care practitioners in Phelan's study. Many studies have examined how experiences with discrimination influence adherence to medical care (Williams \& Mohammed, 2009). Even providers who may not be overtly prejudiced can be discriminatory because of negative racial stereotypes. This may have occurred in this study, which only had one non-Caucasian provider. This is supported by research that found that patients reported higher provider trust and treatment adherence when they saw themselves as similar to their providers (Klonoff, 2009). Thus, increasing the minority staff representation could increase level of elder minority participation. Other researchers have reached similar conclusions (Pardasani, 2004).

The difference in missing baseline data between program completers and noncompleters was an important finding in itself. Program completers were significantly less likely to have missing baseline data than non-completers for all variables. This suggests that it is essential for providers to form relationships right from the beginning through the process of reviewing the baseline data with clients when clients fill out baseline information, and being aware of the baseline levels to individualize treatment as the HEP protocol recommends. This may help strengthen the provider-client relationship, which, in turn, helps program completion and, therefore, health outcomes. However, clients with missing data were also younger, of minority status, unmarried, and with poor health status. Thus, these factors may complicate the process of relationship development. Findings from surveys and focus groups to examine low participation by racial ethnic elders in nutrition programs suggested a lack of trust in filling out intake information (Choi \& Smith, 2004). For the HEP, it may be important for providers to explore how they are connecting with different client subgroups, including exploring culture and language appropriate care issues and conducting more intensive follow-up with minorities to ensure program completion.

Strong provider-client relationships appear to enhance program completion, which adds onto the current literature lack in this area. When asked why elder clients participate in HEP, providers often used words such as trust and caring. Trust is positively correlated to adherence to treatment recommendations, and indirectly, to health status (O'Malley, Sheppard, Schwartz, \& Mandelblatt, 2004). Additionally, the peer support from the health mentor program enhanced program completion. This finding is supported by the randomized trial that showed improved outcomes with senior lay health mentoring for older adults with heart disease (Coull, Taylor, Elton, Murdoch, \& Hargreaves, 2004).

Our multivariate models did not show relational coordination effects on program completion. Unexpectedly, however, our bivariate results showed that higher staff relational coordination was associated with lower program completion. Unlike this study, Gittell's hospital study of surgical patients showed that relational coordination among different providers was significantly 
associated with improved quality of care, decreased lengths of stay, and reduced postoperative pain (Gittell et al., 2000). Our study may have lacked power to show main relational coordination effects due to the low number of sites. Additionally, senior centers may not have the strong need for coordination, integration, and communication that complex hospital settings with high levels of uncertainty require, and the provider roles differ in hospitals and community settings. It appears that for programs such as the HEP, it may not be the coordination or communication between providers that is important to retain clients, but the relationship and connection of clients to the sites and providers.

The limitations of this study bear discussion. We used the 2002-2004 client dataset and interviewed the providers in 2005, however, the HEP was essentially unchanged and providers followed the same protocol. Our baseline client database only asked about minority or nonminority status, and therefore the study findings were restricted to these groups only. We used GEE to deal with the correlated error data issues. These models, however, tend to be less sensitive to the specification of the correlation structure. Obtaining client perspectives on participation was not logistically possible for this study. We were only able to obtain qualitative and quantitative provider perspectives on provider-client relationship and self-efficacy influences on program completion. Because we had more than 15\% missing data for English language, income, and education, we were unable to control for these variables in our analyses, which could have biased our final results. For example, in addition to minority status, lower socio-economic status, income, and education may also play a role in lower program completion. Additionally, our minority population was only $9 \%$ of the final sample, which limits the strength of our findings. Finally, we cannot generalize this study to organizations other than community sites.

Future work is needed to clarify the client perspective and role in provider-client relationships and program completion. The effects of provider ethnicity, active follow-up for minority clients, and health mentor programs on program completion also merit further consideration. Findings on the importance of provider-client relationships suggest that racial-ethnic differences may interfere with program adherence. In particular, we know little about the role of health providers in racial disparities. The opportunity for relationship building during outreach and recruitment also needs further exploration.

\section{CONCLUSIONS AND IMPLICATIONS FOR POLICY AND PRACTICE}

Both provider and client factors contribute to program adherence, which has implications for the design and implementation of community-based programs. Our findings suggest that early focus on clients who show low 
baseline self-efficacy may improve program completion and health outcomes. Early relationship building is also essential. Practitioners should be aware of the possible need for greater follow-up with minority clients to enhance program completion and health outcomes. Results also underscore the need to train and fund more minority providers to ensure improved connection with minority elder clients, and fund and train more health mentor programs to ensure program participation and improved health outcomes. With some similarities to the person-centered model, Klonoff's (2009) recommendations to reduce provider health care bias include seeing each patient as an individual; understanding what their stereotypes are so they can control their influence; increasing providers' confidence in interacting with different racial/ethnic groups who are different from them; improving empathy; and having interaction that is more collaborative, thus leading to better adherence to treatment recommendations. A focus on early relationship building, coupled with increased sensitivity of nonminority providers and aggressive recruiting and training of minority providers will help reach the Healthy People 2010 goal to reduce disparities and to improve participation in health promotion programs.

\section{REFERENCES}

Ainsworth, B. E., \& Youmans, C. P. (2002). Tools for physical activity counseling in medical practice. Obesity Research, 10, 69S-75S.

Bandura, A. (1977). Self-efficacy: Toward a unifying theory of behavioral change. Psychology Review, 84, 191-215.

Beach, M. C., \& Inui, T. (2006). Relationship-centered care. Journal of General Internal Medicine, 21, S3-8.

Brassington, G. S., Atienza, A. A., Perczek, R. E., Lorenzo, T. M., \& King, A. C. (2002). Intervention-related cognitive versus social mediators of exercise adherence in the elderly. American Journal of Preventive Medicine, 23(2S), 80-86.

Carter, W. B., Elward, K., Malmgren, J., Martin, M. L., \& Larson, E. (1991). Participation of older adults in health programs and research: a critical review of the literature. Gerontologist, 31, 584-592.

Castro, C. M., Wilcox, S., O'Sullivan, P., Baumann, K., \& King, A. C. (2002). An exercise program for women who are caring for relatives with dementia. Psychosomatic Medicine, 64, 458-468.

Choi, N. G., \& Smith, J. (2004). Reaching out to racial/ethnic minority older persons for elderly nutrition programs. Journal of Nutrition for the Elderly, 24, 89-105.

Clark, D. O., Stump, T. E., \& Damush, T. M. (2003). Outcomes of an exercise program for older women recruited through primary care. Journal of Aging and Health, 15, 567-585.

Coffey, A., \& Atkinson, P. (1996). Making sense of qualitative data: London: Sage.

Coull, A. J., Taylor, V. H., Elton, R., Murdoch, P. S., \& Hargreaves, A. D. (2004). A randomized controlled trial of senior Lay Health Mentoring in older people 
with ischemic heart disease: The Braveheart Project. Age and Ageing, 33, 348-354.

Curry, L., Shield, R., \& Wetle, T. (Eds.). (2006). Improving aging and public bealth research: qualitative and mixed methods. Washington, DC: American Public Health Association and Geronotological Society of America.

Davis, C., Leveille, S. G., \& Favaro, S. (1998). Benefits to volunteers in a community-based health promotion and chronic illness self-management program for the elderly. Journal of Gerontological Nursing, 24, 16-23.

Duggan, A. (2006). Understanding interpersonal communication processes across health contexts: advances in the last decade and challenges for the next decade. Journal of Health Communication, 11, 93-108.

Eakin, E. G., \& Russel, R. E. (1997). Recruitment of managed care Medicare patients for a physical activity study. American Journal of Health Promotion, 12, 98-101.

Gittell, J. H. (2006). Relational coordination: Coordinating work through relationships of shared knowledge, shared goals, and mutual respect. Northamptom, MA: Edward Elgar.

Gittell, J. H., Fairfield, K. M., Bierbaum, B., Head, W., \& Jackson, R. (2000). Impact of relational coordination on quality of care, postoperative pain and functioning, and length of stay. Medical Care, 38, 807-819.

Grace, S. L., Abbey, S. E., Shnek, Z. M., \& Irvine, J. (2002). Cardiac rehabilitation I: Review of psychosocial factors. General Hospital Psychiatry, 24, 121-126.

Horton, N. J., \& Lipsitz, R. S. (1999). Review of software to fit generalized estimating equation regression models. American Statistician, 53, 160-169.

King, A. C. (2001). Interventions to promote physical activity by older adults. Journals of Gerontology/Series A, 56A (Special Issue II), 36-46.

Klonoff, E. A. (2009). Disparities in the provision of medical care: An outcome in search of an explanation. Journal of Behavioral Medicine, 32, 48-63.

Leonard, N. R., Lester, P., Rotheram-Borus, M. J., Mattes, K., Gwadz, M., et al. (2003). Successful recruitment and retention of participants in longitudinal behavioral research. AIDS Education and Prevention, 15, 269-281.

Leutz, W., Capitman, J., Ruwe, M., Ching, V. N., Flaherty-Robb, M., et al. (2002). Caregiver education and support: Results of a multi-site pilot in an HMO. Home Health Care Services Quarterly, 21(2), 49-72.

Leveille, S. G., Wagner, E. H., Davis, C., Davios, C., Grothaus, L. C., et al. (1998). Preventing disability and managing chronic illness in frail older adults: A randomized trial of a community-based partnership with primary care. Journal of the American Geriatrics Society, 46, 1191-1198.

Long, B. J., Calfas, K. J., \& Wooten, W. (1996). A multisite field test of the acceptability of physical activity counseling in primary care: Project PACE. American Journal of Preventive Medicine, 12, 73-81.

Lorig, K., Gonzalez, V. M., Laurent, D., Morgan, L., \& Laris, B. A. (1998). Arthritis self-management program variations: Three Studies. Arthritis Care and Research, 11, 448-454.

Lorig, K., Ritter, P. L., Stewart, A. L., Sobel, D. S., Brown, B. W., et al. (2001). Chronic disease self-management program: 2-year health status and health care utilization outcomes. Medical Care, 39, 1217-1223. 
Lorig, K., Sobel, D. S., Ritter, P. L., Laurent, D., \& Hobbs, M. (2001). Effect of a self-management program on patients with chronic disease. Effective Clinical Practice, 4, 256-262.

Lorig, K., Sobel, D. S., Stewart, A., Brown, W. B., Bandura, A., et al. (1999). Evidence suggesting that a chronic disease self-management program can improve health status while reducing hospitalization. Medical Care, 37 , $5-14$.

Maddigan, S. L., Majumdar, S. R., \& Johnson, J. A. (2005). Understanding the complex associations between patient-provider relationships, self-care behaviors, and health related quality of life in type 2 diabetes: A structural equation modeling approach. Quality of Life Research, 14, 1489-1415.

Manton, K. G., XiLiang, G., \& Lamb, V. L. (2006). Change in chronic disability from 1982 to 2004/2005 as measured by long-term changes in function and health in the U.S. elderly population. Proceedings of the National Academy of Sciences of the United States of America, 103, 18374-18379.

Marks, R., Allegrante, J. P., \& Lorig, K. (2005a). A review and synthesis of research evidence for self-efficacy enhancing interventions for reducing chronic disability: Implications for health education practice (Part I). Health Promotion Practice, 6, 37-43.

Mills, K. M., Stewart, A. L., King, A. C., Roitz, A. C., \& et al. (1996). Factors associated with enrollment of older adults into a physical activity program. Journal of Aging and Health, 8, 96-113.

Minder, C. E., Muller, R., Gillmann, G., Beck, J. C., \& Stuck, A. E. (2002). Subgroups of refusers in a disability prevention trial in older adults: Baseline and follow-up analysis. American Journal of Public Health, 92, 445-450.

Nolan, M. R., Davies, S., Brown, J., Keady, J., \& Nolan, J. (2004). Beyond "personcentered" care: A new vision for gerontological nursing. International Journal of Older People, in association with Journal of Clinical Nursing, 13(3a), 45-53.

O'Malley, A. S ., Sheppard, V. B., Schwartz, M., \& Mandelblatt, J. (2004). The role of trust in use of preventive services among low-income African-American women. Preventive Medicine, 38, 777-785.

Ory, M. G., Lipman, P. D., Karlen, P. L., Gerety, M. B., Steven, V. J., et al. (2002). Recruitment of older participants in frailty/injury prevention studies. Prevention Science, 3, 1-22.

Pardasani, M. (2004). Senior centers: Increasing minority participation through diversification. Journal of Gerontological Social Work, 43(2/3), 41-56.

Phelan, E. A., Williams, B., Leveille, S. G., Snyder, S., Wagner, E. H., et al. (2002). Outcomes of a community-based dissemination of the health enhancement program. Journal of the American Geriatrics Society, 50, 1519-1524.

Phelan, E. A., Williams, B., Pennix, B. W., LoGerfo, J. P., \& Leveille, S. G. (2004). Activities of daily living function and disability in older adults in a randomized trial of the Health Enhancement Program. Journal of Gerontology: Medical Sciences, 59A, 838-843.

Phelan, E. A., Williams, B., Snyder, S., Fitts, S. S., \& LoGerfo, J. P. (2006). A five state dissemination of a community-based disability prevention program for older adults. Clinical Interventions in Aging, 1, 267-274. 
Prohaska, T. R., Peters, K., \& Warren, J. S. (2000). Sources of attrition in a churchbased exercise program for older African Americans. American Journal of Health Promotion, 14, 380-385.

Stewart, M., Brown, J. B., \& Donner, A. (2000). The impact of patient-centered care on outcomes. Journal of Family Practice, 49, 796-804.

Stuck, A. E., Walthert, J. M., \& Nikolaus, T. (1999). Risk factors for functional status decline in community-living elderly people: A systematic literature review. Social Science and Medicine, 48, 445-469.

Von Korff, M., Gruman, J., Schaefer, J., Curry, S. J., \& Wagner, E. H. (1997). Collaborative management of chronic illnesses. Annals of Internal Medicine, 127, 1097-1102.

Wagner, E. H., Grothaus, L. C., Hecht, J. A., \& LaCroix, A. Z. (1991). Factors associated with participation in a senior health promotion program. Gerontologist, 31, 598-602.

Ware, J. E., \& Sherbourne, C. D. (1992). The MOS 36-item short-form health survey (SF-36). I. Conceptual framework and item selection. Medical Care, 30, 473-483.

Weinberg, D. B., Lusenhop, R. W., Gittell, J. H., \& Kautz, C. M. (2007). Coordination between formal providers and informal caregivers. Healthcare Management Review, 32, 140-149.

Williams, D. R., \& Mohammed, S. A. (2009). Discrimination and racial disparities in health: evidence and needed research. Journal of Behavioral Medicine, 32, $20-47$.

Yesavage, J. A., Brink, T. L., \& Rose, T. L. (1982). Development and validation of a geriatric depression screening scale: A preliminary report. Journal of Psychiatric Research, 17, 37-49. 